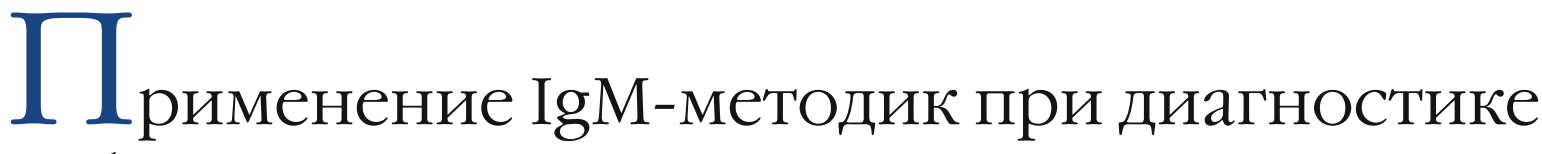 сифилиса
}

\author{
С.В. Ротанов ${ }^{1,2}$, Ф.А. Эрматова ${ }^{2}$
}

1 ФГБУ «Государственный научный центр дерматовенерологии и косметологии» Минздрава России 107076, Москва, ул. Короленко, д. 3, стр. 6

2 ГБОУ ВПО «Российский национальный исследовательский медицинский университет им. Н.И. Пирогова» Минздрава России

117997, Москва, ул. Островитянова, д. 1

Представлены результаты анкетного опроса, проведенного в серологических лабораториях 60 дерматовенерологических учреждений субъектов Российской Федерации, о применении современных методик определения антител класса М для диагностики раннего сифилиса. Установлено, что определение трепонемоспецифических антител класса М проводили в 86,67\% лабораторий: метод ИФА Суммарное количество IgM-исследований не превышало 1,30\% от всего объема иммунохимических реакций для диагностики сифилиса, проведенных в лабораториях в 2012 г.; в структуре IgM-методов преобладало использование ИФА ${ }_{\lg }-97,27 \%$, в то время как частота использования РИФ Установленные соотношения, по нашему мнению, были обусловлены отсутствием в рассматриваемый период (в 2012 г.) производственного выпуска разрешенных к применению наборов реагентов российского производства для

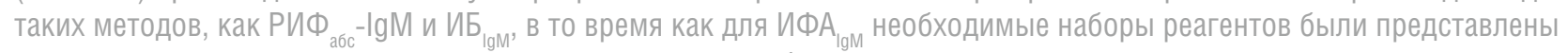
в широком ассортименте, а сам метод использовался в лабораториях в течение длительного времени.

Ключевые слова: сифилис, клиническая лабораторная диагностика, иммунохимические исследования, иммуноглобулины класса М. 
U

\title{
sing IgM methods in the diagnostics of syphilis
}

\author{
S.V. Rotanov ${ }^{1,2}$, F.A. Ermatova ${ }^{2}$
}

${ }^{1}$ State Research Center of Dermatovenereology and Cosmetology, Ministry of Healthcare of the Russian Federation Korolenko str., 3, bldg 6, Moscow, 107076, Russia

${ }^{2}$ The Russian National Research Medical University named after N.I. Pirogov (RNRMU)

Ostrovityanova str., 1, Moscow, 117997, Russia

The authors present the results of a questionnaire survey conducted in serological laboratories in 60 dermatovenerology enterprises in the subjects of the Russian Federation on the use of up-to-date methods for the determination of Class M antibodies for the diagnostics of early syphilis. It was revealed that treponemal specific Class M antibodies were determined in $86.67 \%$ of laboratories: the ElAlgM method was used in $86.67 \%$ of laboratories, IBIgM — in $18.33 \%$, and PHTIgM — in $6.67 \%$ of laboratories only. The total number of IgM tests did not exceed $1.3 \%$ of the entire volume of immunochemical reactions conducted for the diagnostics of syphilis in laboratories in 2012; as for IgM methods, the use of EIAlgM prevailed - 97.27\% while the frequency of using PHTIgM and IBIgM was 2.0 and $0.73 \%$, respectively.

In the authors' opinion, such ratios were stipulated by the absence of production of kits made in Russia during the study period (in 2012) and allowed for use for methods such as PHTIgM and IBIgM while there was a wide choice of kits required for ElAlgM and laboratories had a long-term experience of using this method.

Key words: syphilis, clinical laboratory diagnostics, immunochemical tests, Class M immunoglobulins.

Corresponding author: rotanov@cnikvi.ru. Vestnik Dermatologii i Venerologii 2015; 4: 83—89. 
В Российской Федерации первичное обследование населения с целью выявления больных сифилисом проводят в медицинских организациях, оказывающих первичную медико-санитарную помощь. Специализированную медицинскую помощь этим больным с установлением клинического диагноза по преемственности осуществляют в медицинских организациях, специализированных по профилю «дерматовенерология» [1-3].

Первичный скрининг сифилиса, подтверждение специфического характера клинических проявлений, обнаруженных у больного, а также установление клинического диагноза проводят на основе результатов лабораторных иммунохимических (серологических) исследований, основанных на определении в крови специфических иммуноглобулинов (lg) к антигенам возбудителя сифилиса, T. pallidum, в основном IgG или суммарного пула $\lg (\lg G, \lg M$ и $\lg \mathrm{A})$. Однако для диагностики раннего сифилиса целесообразно определять в сыворотке крови специфические $\operatorname{lgM}$, так как первичный адаптивный иммунный ответ у человека на инфицирование T. pallidum происходит путем выработки специфических антител класса М, а появление специфических антител классов $\mathrm{G}$ и А происходит несколько позднее [4-9].

Для выявления специфических антител класса $\mathrm{G}$ или суммарного пула антител разных классов (G, M и A) при сисрилисе применяют: иммуноферментный анализ (ИФА), реакцию пассивной гемагглютинации (РПГА), реакцию связывания комплемента с трепонемным антигеном $\left(\mathrm{PCK}_{\text {треп }}\right)$ и реакцию непрямой иммунофлюоресценции (РИФ), иммуноблоттинг (ИБ), иммунохроматографические и иммунохемилюминесцентные исследования [6, 10-15]. Перечисленные методы лабораторных исследований применяются при диагностике сифилиса уже длительное время, и они изучены в большей степени, нежели относительно новые модификации этих методов клинического исследования путем определения специфических IgM. Это обусловлено более ранним созданием конъюгатов, сенсибилизированных к Ig человека или несвязанному Fc-фррагменту молекулы IgG, и трудностями разработки высокочувствительных технологий для определения специфических $\lg \mathrm{M}$.

Диффреренцированное определение антитрепонемных IgM для диагностики раннего сифилиса стало возможным благодаря развитию технологий получения на лабораторных животных высокоспецифичных моноклональных антител к $\mu$-фрорме тяжелой аминокислотной цепи в структуре IgM [16-18].

Разработка и внедрение в практическое здравоохранение специфичных и чувствительных модификаций современных клинических лабораторных методов определения IgМ для диагностики сифилиса и необходимых для этого наборов реагентов позволило провести настоящее исследование.
Цель исследования: изучение частоты применения современных IgM-модификаций иммунохимических методов исследования для ранней диагностики сифилиса (ИФА, РИФ и ИБ) в медицинских дерматовенерологических организациях субъектов Российской Федерации.

\section{Материал и методы}

Для проведения работы в ФГБУ «ГНЦДК» Минздрава России были разработаны анкеты, содержавшие вопросы по применению современных иммунохимических исследований при сифилисе, для серологических лабораторий и клинических отделений. Эти анкеты в 2013 г. были направлены в специализированные медицинские дерматовенерологические организации 83 субъектов Российской Федерации.

При оценке потребности учреждений практического здравоохранения в применении лабораторных методик определения трепонемоспецифических IgM для ранней диагностики сифилиса были использованы данные официальной государственной статистической отчетности Минздрава России о заболеваемости населения страны ранним сифилисом в 2012 г. [19].

\section{Результаты исследования}

По результатам проведения анкетного опроса о применении лабораторных иммунохимических исследований при диагностике раннего сифилиса и количестве этих исследований, выполненных в течение одного календарного года (2012 г.), заполненные анкеты были получены от 60 (72,3\%) из 83 соответствующих медицинских организаций 8 федеральных округов (ФО) Российской Федерации. В 7 федеральных округах в анкетном опросе приняли участие от 54,5 до $85,7 \%$ специализированных дерматовенерологических медицинских организаций субъекта, а в одном (Южном ФО) - только 33,3\%, что тем не менее позволило оценить представленные данные как репрезентативные для объективной характеристики состояния проблемы как по большинству отдельных фредеральных округов, так и по России в целом.

При анализе материалов анкет установлено, что современные специфические иммунохимические методы при диагностике сифилиса применялись с разной интенсивностью: ИФА - в 100,0\%, РПГА - в 91,7\%, РИФ - в 75,0\%, РСК треп - в 45,0\% обследованных лабораторий, в то время как ИБ - только в 28,3\%, а иммунохемилюминесцентные исследования и реакция иммобилизации трепонем (РИТ) - по 0,3\% лабораторий дерматовенерологических медицинских организаций. Нетрепонемные исследования с кардиолипиновым антигеном при обследовании на сифилис проводили во всех лабораториях (в 100\%): в модификации реакции микропреципитации (РМП) - в 96,7\%, в ре- 
акции связывания комплемента (PCK кард $)$ - в 45,0\% и быстром плазмареагиновом тесте (РПР) - в 28,3\% лабораторий.

Нами было определено общее количество лабораторий дерматовенерологических организаций субъектов России, регулярно применявших IgM-методы исследования для диагностики сифилиса. Установлено, что определение трепонемоспецифических антител класса М проводили в 52 (86,67\%) лабораториях, предоставивших заполненные анкеты: метод ИФА в 52 лабораториях (86,67\%), ИБ $Б_{\operatorname{lgm}}$ - в 11 (18,33\%) и РИФ

Также различалось и общее количество исследований, выполненных каждым методом в течение календарного года. Максимальное количество исследований при обследовании на сифилис в 2012 г. было проведено с использованием тестов на основе кардиолипинового антигена - 57,79\% (в том числе в РМП 43,56\%, в РСК кард - 10,70 и в РПР - 3,53\%). Среди всех исследований в трепонемоспецифических тестах $(42,21 \%)$ определения антител в ИФА составили значительную часть - 23,08\%, другие методы исследования были представлены в меньших количествах: РСК $_{\text {треп }}-10,84 \%$, РПГА - 6,74\%, РИФ - 1,36\%, ИБ 0,03\%, а иммунохемилюминесцентные исследования и РИТ - 0,09 и 0,07\% соответственно.

Среди всего объема иммунохимических реакций для диагностики сифилиса, проведенных в обследованных лабораториях (12 893 990; 100\%), IgMтесты составили очень небольшую часть - 1,30\% (167 451 ед.). В структуре применения IgM-тестов преобладали исследования в ИФА $\mathrm{IgM}_{-}-97,27 \%$ (162 879 анализов), небольшую долю составили исследования в РИФ $\Phi_{\operatorname{lgm}}$ и ИБ lgм $_{\text {lg }}$ - 2,0\% (3355) и 0,73\% (1217) соответственно. Установленные соотношения, по нашему мнению, были обусловлены отсутствием в 2012 г. производственного выпуска разрешенных к применению наборов реагентов российского производства для таких методов, как РИФ $\Phi_{\text {абс }}-\lg M$ и ИБ ${ }_{\text {lgм }}$, в то время как для ИФА ${ }_{\text {Igм }}$ необходимые наборы реагентов были представлены на соответствующем рынке в широком ассортименте, а сам метод использовался в лабораториях уже в течение длительного времени.

Интересные данные получены при оценке доли применения IgМ-модификаций определения антител каждым из трех методов для диагностики сифилиса:

из 2976273 (100\%) исследований, выполненных методом ИФА, количество исследований по определению специфических к T. pallidum антител всех классов суммарно $(G+M+A)$ составило 2585723 (86,88\%), а диффреренцированно $\lg G-227671$ (7,65\%) и $\lg \mathrm{M}-162879$ (5,47\%);

методом РИФ было проведено 174936 (100\%) исследований, в том числе РИФ $\Phi_{\text {lgG }}\left(\right.$ РИФ $\Phi_{\text {абс }}$ и $\left.Р И \Phi_{200}\right)-$ $171581(98,08 \%)$ и РИФ $\Phi_{\operatorname{lgm}}-3355$ (1,92\%); методом ИБ проведено 3663 (100\%) определения трепонемоспецифических антител, в том числе с выявлением IgG - 2446 (66,78\%) и $\lg \mathrm{M}-1217$ (33,22\%).

Выявленные показатели подтвердили актуальность проведения нашего исследования, так как продемонстрировали заинтересованность практического здравоохранения в применении высокочувствительных методов детекции антитрепонемных IgМ для диагностики сифилиса, к числу которых относится ИБ (несмотря на достаточно высокую себестоимость проведения этого теста).

Анализ данных анкетного опроса в разрезе отдельных фредеральных округов Российской Федерации также показал, что наибольшее количество исследований для выявления IgM к антигенам T. pallidum во всех медицинских лабораториях было проведено

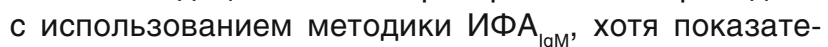
ли применения этих модификаций тестов среди всего объема исследований методом ИФА существенно различались. Наименьшую долю применения ИФА (1,96\%) наблюдали в лабораториях дерматовенерологических организаций в Южном ФО, а максимальную (13,06\%) - в соответствующих лабораториях в Северо-Кавказском ФО; в других административных регионах показатели варьировали от 3,13 и 3,72\% (в Северо-Западном и Центральном ФО соответственно) до 5,96 и $6,47 \%$ (в Приволжском и Дальневосточном ФО соответственно) и до 7,65 и 7,99\% (в Уральском и Сибирском ФО соответственно).

Исследование в РИФ са не проводили в лабораториях дерматовенерологических организаций в Южном, Северо-Кавказском, Уральском, Сибирском и Дальневосточном ФО; минимальную долю $(0,78 \%)$ эта модификация занимала в общем объеме исследований методом РИФ в соответствующих лабораториях медицинских организаций в Центральном ФО и более существенную часть $(4,95$ и 7,22\%) в Северо-Западном и Приволжском ФО соответственно.

Методику определения антител класса М в ИБ при диагностике сифилиса не применяли в специализированных медицинских дерматовенерологических организациях в Северо-Западном и Северо-Кавказском ФО, небольшую долю от общего объема исследований в ИБ составляли исследования в ИБ-IgМ в Уральском и Центральном ФО (1,29 и 8,84\% соответственно), несколько больше исследований проведено в Сибирском, Дальневосточном и Приволжском ФО (12,22; 15,55 и 19,11\% соответственно), максимальное количество (50\%) - в лабораториях Южного ФО.

Для количественной характеристики реальных потребностей практического здравоохранения в трепонемоспецифических IgM-исследованиях нами был осуществлен расчет количества тестов, выполненных в 2012 г. каждым методом, в пересчете на один вновь 
выявленный клинический случай раннего сифилиса. Это обусловлено тем, что клинические проявления ряда вирусных и бактериальных инфекций, а также дерматозов в ряде случаев сходны с проявлениями раннего сифилиса, что требует проведения дополнительного лабораторного обследования пациентов при дифференциальной диагностике для установления специфического характера выявленных поражений.

Установлено, что при лабораторном обследовании населения в специализированных дерматовенерологических организациях и постановке одного случая клинического диагноза раннего сифилиса по России в целом проводили 6,86 определения IgM к антигенам $T$. pallidum, в том числе в ИФА ${ }_{\text {Igм }}-6,68$, в РИФ абс $-\lg M-0,14$, а в ИБ

Анализ частоты использования IgМ-методик показал, что в 2012 г. они наиболее интенсивно применялись в регионах России с наиболее высоким уровнем заболеваемости населения ранним сифилисом: в Центральном, Приволжском, Северо-Западном, Дальневосточном и Сибирском ФО (7,91; 7,90; 6,86; 6,67 и 6,54 ед. соответственно), в которых было установлено 3796, 6392, 1130, 3043 и 67058 случаев раннего сифилиса соответственно [19]. В то время как в федеральных округах с более низкими показателями заболеваемости ранним сифилисом: Уральском, Северо-Кавказском и Южном (1574, 922 и 829 случаев соответственно) клинических лабораторных исследований с определением трепонемоспецифических IgM было проведено меньше: 4,21; 5,28 и 4,19 ед. в расчете на 1 вновь диагностированный случай раннего сифилиса.

Постепенное внедрение в практическое здравоохранение отечественных наборов реагентов для современных методик определения специфических IgM при диагностике раннего сифилиса позволит нивелировать выявленные различия в частоте применения этих диагностических исследований. По нашим представлениям, количество исследований в модификации РИФ $\Phi_{\operatorname{lgm}}$ в специализированных дерматовенерологических организациях при диагностике сифилиса будет постепенно приближаться к количеству исследований в ИФА ${ }_{\mathrm{lgM}}$, в то время как прирост количества по-

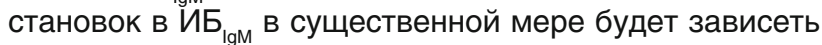
от снижения стоимости наборов реагентов для этого дорогостоящего исследования.

\section{Выводы}

1. В подавляющем большинстве дерматовенерологических организаций субъектов Российской Федерации в 2012 г. для диагностики сифилиса применяли

\section{$\begin{array}{ll}\text { Данные о количестве иммунохимических исследований в ИФА } & \text { В РИФ } \\ \text { Таблица } & \text { в лабораториях дерматовенерологических организаций субъектов Российской Федерации в } 2012 \text { г., } \\ \text { в расчете на } 1 \text { выявленный клинический случай раннего сифилиса }\end{array}$}

\begin{tabular}{|c|c|c|c|c|c|c|c|c|c|}
\hline \multirow{3}{*}{$\begin{array}{l}\text { Федеральный } \\
\text { округ России }\end{array}$} & \multirow{3}{*}{$\begin{array}{c}\text { Общее число } \\
\text { выявленных } \\
\text { случаев } \\
\text { ранних } \\
\text { форм } \\
\text { сифилиса } \\
\text { в } 2012 \text { г.* }\end{array}$} & \multicolumn{8}{|c|}{$\begin{array}{c}\text { Количество иммунохимических исследований для диагностики сифилиса, выполненных } \\
\text { в лабораториях медицинских организаций соответствующего федерального округа России } \\
\text { (данные проведенного анкетного опроса) }\end{array}$} \\
\hline & & \multicolumn{2}{|c|}{$\begin{array}{c}\text { всеми методами } \\
\left(И Ф A_{\operatorname{lgM}}, Р И \Phi_{\operatorname{lgM}}, \text { ИБ }{ }_{\operatorname{lgm}}\right)\end{array}$} & \multicolumn{2}{|c|}{ методом ИФА } & \multicolumn{2}{|c|}{ методом РИФ } & \multicolumn{2}{|c|}{ методом ИБ } \\
\hline & & всего & $\begin{array}{c}\text { в расчете } \\
\text { на } \\
1 \text { случай } \\
\text { раннего } \\
\text { сифилиса }\end{array}$ & всего & $\begin{array}{c}\text { в расчете } \\
\text { на } \\
1 \text { случай } \\
\text { раннего } \\
\text { сифилиса }\end{array}$ & всего & $\begin{array}{c}\text { в расчете } \\
\text { на } \\
1 \text { случай } \\
\text { раннего } \\
\text { сифилиса }\end{array}$ & всего & $\begin{array}{c}\text { в расчете } \\
\text { на } \\
1 \text { случай } \\
\text { раннего } \\
\text { сифрилиса }\end{array}$ \\
\hline ЦФО & 3796 & 30020 & 7,91 & 29464 & 7,76 & 540 & 0,14 & 16 & 0,004 \\
\hline СЗФО & 1130 & 7749 & 6,86 & 7309 & 6,47 & 440 & 0,39 & 0 & 0 \\
\hline ЮФ0 & 829 & 3477 & 4,19 & 3465 & 4,18 & 0 & 0 & 12 & 0,01 \\
\hline СКФ0 & 922 & 4869 & 5,28 & 4869 & 5,28 & 0 & 0 & 0 & 0 \\
\hline ПрФ0 & 6392 & 50526 & 7,90 & 47142 & 7,38 & 2375 & 0,37 & 1009 & 0,16 \\
\hline УФ0 & 1574 & 6631 & 4,21 & 6561 & 4,17 & 0 & 0 & 70 & 0,05 \\
\hline СФО & 6705 & 43868 & 6,54 & 43809 & 6,53 & 0 & 0 & 59 & 0,01 \\
\hline ДВФО & 3043 & 20311 & 6,67 & 20260 & 6,66 & 0 & 0 & 51 & 0,02 \\
\hline Всего по РФ & 24401 & 167451 & 6,86 & 162879 & 6,68 & 3355 & 0,14 & 1217 & 0,05 \\
\hline
\end{tabular}

* Данные офрициальной государственной статистической отчетности Минздрава России [19]. 
современные методики исследования: иммуноферментный анализ (ИФА) - в 100\% и реакцию непрямой иммуносрлюоресценции (РИФ) - в 75\% лабораторий, в то время как иммуноблоттинг (ИБ) - только в 28,33\% лабораторий. Доля исследований в ИФА составила 23,08\%, в РИФ - 1,36\% и в ИБ - 0,03\% от общего количества иммунохимических исследований на сифилис.

2. Определение трепонемоспецифических антител класса М в ИФА в ИБ $Б_{\operatorname{lgm}}$ - в $18,33 \%$ и в РИФ бораторий. Суммарное количество проведенных IgMисследований не превышало 1,30\% от общего количества иммунохимических исследований для диагностики сифилиса.

3. В структуре IgМ-методов при обследовании на сифилис преобладало использование ИФА $\mathrm{IgM}_{-}$ $97,27 \%$, в то время как частота применения РИФ и ИБ ${ }_{\text {Igм }}$ составила только 2,0 и 0,73\% соответственно.
4. Недостаточное применение IgM технологий определения трепонемоспецифических IgM при верифрикации положительных результатов скрининговых обследований и при уточнении клинического диагноза, по нашему мнению, в значительной степени обусловлено отсутствием производственного выпуска разрешенных к применению отечественных наборов реагентов для выполнения ряда диагностических методик.

5. По России в целом при обследовании населения в специализированных дерматовенерологических организациях и постановке одного случая клинического диагноза раннего сифилиса в 2012 г. количество исследований по определению $\lg$ к антигенам T. pallidum составило 6,86, в том числе в ИФА $\mathrm{lgm}_{\text {- }}$ 6,68 , в РИФ абс $-\lg \mathrm{M}-0,14$, а в ИБ ваний; эти показатели могут быть использованы при планировании работы в клинических диагностических лабораториях. І
1. Federal law No. 323-FZ dated 21.11.2011 "On the basis of health protection in the Russian Federation". Collected legislation of the Russian Federation, 2011, №. 48, article 6724. [Федеральный закон № 323-Ф3 от 21.11.2011 г. «Об основах охраны здоровья граждан в Российской Федерации». Собрание законодательства Российской Федерации, 2011, № 48, ст. 6724.]

2. Order of the Ministry of health and social development of the Russian Federation No.543-n dated 15.05.2012 "On approval of the Regulations on the organization providing primary health care to the adult population [Приказ Министерства здравоохранения и социального развития Российской Федерации № 543н от 15.05.2012 г. «0б утверждении Положения об организации оказания первичной медикосанитарной помощи взрослому населению».]

3. Order of the Ministry of health of the Russian Federation No. 942-n dated 15.11.2012 "On approval of the Procedure of rendering of medical aid to the population in the profile "dermatovenerology" (registered No. 26302 in the Ministry of justice of Russia 21.12.2012). "Russian gaseta", spec. issue №. 78/1, 11.04.2013. [Приказ Министерства здравоохранения Российской Федерации № 924н от 15.11.2012 г. «0б утверждении Порядка оказания медицинской помощи населению по профилю "дерматовенерология"» (зарегистрирован № 26302 в Министерстве юстиции России 21.12.2012 г.). Российская газета, спец. выпуск, № 78/1, от 11.04.2013.]

\section{Литература}

4. Luger A. Serological diagnosis of syphilis; current methods. In: Young H., McMillan A. (Eds.). Immunological diagnosis of sexually transmitted diseases. N-Y: Marcel Dekker 1998: 249—274.

5. Egglestone S.I., Turner A.J.L. Serological diagnosis of syphilis. Commun Dis Public Health 2000; 3: 158-162.

6. Young $\mathrm{H}$. Guidelines for serological testing for syphilis. Sex Transm Inf 2000; 76: 403-405.

7. Goh B.T., van Voorst Vader P.C. European Guideline for the management of syphilis. Int J of STD \& AIDS 2001; 12 (Suppl. 3): 14-26.

8. Serdjuckaja M.B., Ivanov A.M., Ovsyannikov F.A. Gupalova T.V., Hodosevich E.V. Method of increasing the sensitivity of detection of $\operatorname{lgM}$ antibodies in the diagnosis of congenital syphilis. Russian journal of immunology 2007; 9 (Suppl 1): 128-129. [Сердюцкая М.В., Иванов А.М., Овсянников Ф.А., Гупалова Т.В., Х0досевич Е.В. Метод повышения чувствительности детекции IgM-антител при диагностике врожденного сифилиса. Российский иммунологический журнал 2007; 9 (1): 128-129.]

9. Krasnoselskikh T.V., Sokolovskiy E.B. Modern syphilis: epidemiological trends achievements in the study of Treponema pallidum. Probl modern dermatol, venereol and cosmetol 2010; 1: 84-87. [Красносельских Т.В., Соколовский Е.В. Современный сифилис: эпидемиологические тенденции и достижения в области изучения Treponema pallidum. Пробл соврем дерматол, венерол косметол 2010; (1): $84-87$.
10. Larsen S.A. (Ed.), Pope V., Johnson R.E., Kennedy E.J. Manual of tests for syphilis. 9th ed. Washington: DC, American Health Association, 1998.

11. Order of the Ministry of health of the Russian Federation No. 87 dated 26.03.2001 "On improving serological diagnosis of syphilis" (Annex 1 of "Setting the selection and diagnostic tests for syphilis." [Приказ Министерства здравоохранения Российской Федерации № 87 от 26.03.2001 г. «0 совершенствовании серологической диагностики сисрилиса» (Приложение 1 «Постановка отборочных и диагностических тестов на сифилис»).]

12. Lomonosov K.M. Actual interview. New in the diagnosis and treatment of syphilis. Rus j skin and venere dis 2002; 5: 56-60. [Ломоносов K.M. Актуальное интервью. Новое в диагностике и терапии сифилиса. Рос журн кожн вен бол 2002; (5): 56-60.]

13. Kingston M., French P., Goh B. UK National Guidelines of the Management of Syphilis 2008. Int J of STD \& AIDS 2008 (Nov); 19: 729_740.

14. Kitaeva N.V., Frigo N.V., Melechina L.E. Actual problems of syphilidology. Modern techniques for the diagnosis of syphilis infection. Vestn of dermatol venereal 2008; 5: 51—59. [Китаева Н.В., Фриго Н.В., Мелехина Л.Е. Актуальные проблемы сифилидологии. Современные технологии диагностики сифилитической инсеекции. Вестн дерматол венерол 2008; (5): 51—59]. 
15. Frigo N.V., Rotanov S.V., Manukyan T.E., Katunin G.L., Suvorova A.A., Volkov I.A., Kitaeva N.V. Laboratory diagnosis of syphilis: yesterday, today and tomorrow. Vestn dermatol venereal 2012; 4: 16-23. [Фриго Н.В., Ротанов С.В., Манукьян Т.Е., Катунин Г.Л., Суворова А.А., Волков И.А., Китаева Н.В. Лабораторная диагностика сифилиса: вчера, сегодня, завтра. Вестн дерматол венерол 2012; (4): 16-23.]

16. Lyakhov V.F., Borisenko K.K., Potekaev N.N. et al. Dynamics anti-treponemal immunoglobulinemia with early forms of syphilis. Vestn dermatol venereal 1990; 8: 38 — 42. [Ляхов В.Ф., Борисенко К.К., Потекаев Н.С. и др. Динамика трепонемоспецифической иммуноглобулинемии при ранних формах сифилиса. Вестн дерматол венерол 1990; (8): 38-42.]
17. Sidorova E.V., Lyakhov V.F. The value of determination anti-treponemal IgM antibodies in the serodiagnosing of syphilis. STD 1995; 4: 11-14. [Сидорова Е.В., Ляхов В.Ф. Значение определения противотрепонемных IgMантител в серодиагностике сифилиса. ЗППП 1995; (4): 11—14.]

18. Tkachev V.K., Vyatkin T.G. ELISA test for diagnosis of syphilis: information guide. 3rd ed., 2005. URL: http://www.vector-best.ru/brosh/9607.htm [Ткачев В.К., Вяткина Т.Г. ИФА-диагностика сифилиса: информационно-методическое пособие. 3-е изд., 2005. URL: http://www. vector-best.ru/brosh/9607.htm.]
19. Resources and activity dermatological medical organizations profile. The incidence of sexually transmitted diseases, infectious skin diseases and diseases of the skin for 2011-2012 [Statistics]. M: The Ministry of health of Russia, 2013. [Ресурсы и деятельность медицинских организаций дерматовенерологического профиля. Заболеваемость инфекциями, передаваемыми половым путем, заразными кожными болезнями и болезнями кожи за 2011-2012 гг. [Статистические материалы]. М: Минздрав России, ФГБУ «ЦНИИОИЗ» Минздрава России, ФГБУ «ГНЦДК» Минздрава России, 2013.]

об авторах:

С.В. Ротанов - д.м.Н., доцент, врач клинической лабораторной диагностики ФГБУ «ГНЦДК» Минздрава России, профессор кафедры дерматовенерологии лечебного факультета ГБОУ ВПО РНИМУ им. Н.И. Пирогова Минздрава России, Москва

Ф.А. Эрматова - аспирант кафедры дерматовенерологии лечебного фракультета ГБоУ ВПо РНИМУ им. Н.И. Пирогова

Минздрава России, Москва

\section{Конфликт интересов}

Авторы заявляют об отсутствии потенциального конфликта интересов, требующего раскрытия в данной статье 